\title{
A Non-Conserved p33 Protein of Citrus Tristeza Virus Interacts with Multiple Viral Partners
}

\author{
Thi Nguyet Minh Dao, Sung-Hwan Kang, Aurélie Bak, and Svetlana Y. Folimonova ${ }^{\dagger}$ \\ University of Florida, Plant Pathology Department, Gainesville, FL 32611, U.S.A. \\ Accepted 3 March 2020.
}

\begin{abstract}
The RNA genome of citrus tristeza virus (CTV), one of the most damaging viral pathogens of citrus, contains 12 open reading frames resulting in production of at least 19 proteins. Previous studies on the intraviral interactome of CTV revealed selfinteraction of the viral RNA-dependent RNA polymerase, the major coat protein $(\mathrm{CP})$, p20, p23, and p33 proteins, while heterologous interactions between the CTV proteins have not been characterized. In this work, we examined interactions between the $\mathrm{p33}$ protein, a nonconserved protein of $\mathrm{CTV}$, which performs multiple functions in the virus infection cycle and is needed for virus ability to infect the extended host range, with other CTV proteins shown to mediate virus interactions with its plant hosts. Using yeast two-hybrid, bimolecular fluorescence complementation, and coimmunoprecipitation assays, we demonstrated that p33 interacts with three viral proteins, i.e., CP, p20, and p23, in vivo and in planta. Coexpression of $\mathrm{p33}$, which is an integral membrane protein, resulted in a shift in the localization of the p20 and p23 proteins toward the subcellular crude-membrane fraction. Upon CTV infection, the four proteins colocalized in the CTV replication factories. In addition, three of them, CP, p20, and p23, were found in the p33-formed membranous structures. Using bioinformatic analyses and mutagenesis, we found that the $\mathrm{N}$-terminus of p33 is involved in the interactions with all three protein partners. A potential role of these interactions in virus ability to infect the extended host range is discussed.
\end{abstract}

Keywords: citrus tristeza virus, plant virus, protein-protein interaction, viral replication complex

Citrus tristeza virus (CTV) is one of the most economically important pathogens of citrus. CTV belongs to the family Closteroviridae, which comprises plant viruses with

Any opinions, findings, and conclusions or recommendations expressed in this material are those of the author(s) and do not necessarily reflect the views of the National Science Foundation.

Current address for Aurélie Bak: Department of Plant Pathology, University of California, Davis, CA 95616, U.S.A.

${ }^{\dagger}$ Corresponding author: S. Folimonova; svetlana@ufl.edu

Funding: This research was supported by the National Science Foundation Division of Molecular and Cellular Biosciences under grant number 1615723 (to S. Y. Folimonova).

*The $\boldsymbol{e}$-Xtra logo stands for "electronic extra" and indicates that four supplementary figures and three supplementary tables are published online.

The author(s) declare no conflict of interest.

๑) 2020 The American Phytopathological Society the largest positive-stranded RNA genomes (Agranovsky 1996; Bar-Joseph et al. 1979; Dolja et al. 1994, 2006; Karasev 2000). The natural host range of CTV is limited to Citrus spp., in which the virus infects phloem-associated cells. Depending on the virus isolate-citrus scion/rootstock combination, CTV induces a number of host reactions, ranging from none to yellowing of young seedlings, to the abnormal differentiation of the vascular system and the development of stem pits along with small unmarketable fruit, to a quick collapse or decline of the infected trees (Moreno et al. 2008). In recent years, a significant progress has been made toward understanding the interactions in the CTV-citrus pathosystem, including the implication of specific viral gene products in different viral processes and symptom production, characterization of virus movement and distribution in different citrus varieties, and observation of interactions within CTV populations composed of multiple virus strains (Bak and Folimonova 2015; Bergua et al. 2016; Dawson et al. 2013; Kang et al. 2019; Sun and Folimonova 2019). However, knowledge of the molecular mechanisms of the CTV diseases remains obscure.

The CTV genome contains 12 open reading frames (ORFs) (Fig. 1) that can be grouped into the two sets of conserved genes: the "replication gene block"-ORF 1a, which encodes a polyprotein containing two papain-like protease domains L1 and L2, a methyltransferase-like and a helicase-like domains, and ORF $1 \mathrm{~b}$ that generates an RNA-dependent RNA polymerase (RdRp) upon a +1 translational frameshift in the preceding ORF 1a-and the "quintuple gene module" consisting of the ORFs encoding p6, HSP70h, p61, the minor and major coat proteins, $\mathrm{CPm}$ and $\mathrm{CP}$, respectively, involved in virion assembly and movement-plus five additional nonconserved genes, i.e., p33, p18, p13, p20, and p23 (Alzhanova et al. 2000; Hilf et al. 1995; Karasev et al. 1995, 1997; Peremyslov et al. 2004; Satyanarayana et al. 2000, 2004; Tatineni et al. 2010). The p20 and p23 proteins participate in suppression of host RNA silencing along with CP (Lu et al. 2004). The p33, p18, and $\mathrm{p} 13$ proteins are required for infection of a broader range of citrus varieties, yet their functions and action mechanisms are largely unknown (Tatineni et al. 2008, 2011).

Among those viral proteins, p33 has been a focus of our most-recent research efforts. We showed that p33 is an integral membrane protein, and its membrane association confers virus ability to extend its host range (Kang et al. 2015). Furthermore, p33 shares characteristics of viral movement proteins, such as plasmodesmata localization and the ability to form extracellular tubules (Bak and Folimonova 2015). The p33 protein plays a major role in CTV superinfection exclusion (Folimonova et al. 2010) and appears to be a viral effector that influences CTV pathogenicity by modulating a host immune response (Sun and Folimonova 2019). It is likely that most, if not all, functions of this viral protein are mediated through its interaction with other 
viral or host proteins. Yet, to date, none of such interactions has been revealed.

Examination of protein-protein interactions in virus-host systems and their cellular localization could aid the understanding of their biological functions and the virus pathogenesis in general as well as lead to the development of new strategies to protect hosts from virus infections by disrupting these interactions. Proteins can establish stable or transient interactions, and some of them can have multiple partners interacting simultaneously or at different times (Brito and Pinney 2017). The latter seems particularly true for viral proteins; viruses have rather limited genomic capacity while performing a large set of functions during their infection cycles, which also correlates with the often-observed multidomain nature of virusencoded proteins. With CTV, earlier studies examining the intraviral interactome showed self-interaction of the CP, p20, p23, and RdRp (Çevik 2013; Gowda et al. 2000; Nchongboh et al. 2014; Ruiz-Ruiz et al. 2018). These studies, however, largely relied on the yeast two-hybrid (YTH) method, which is incompatible with certain proteins, including membraneassociated proteins (Stagljar and Fields 2002), and could thus have resulted in some additional interactions being missed in those experiments. For the latter reason, we re-evaluated the protein-protein interaction property of $\mathrm{p} 33$ by using its truncated version lacking the $\mathrm{C}$-terminal transmembrane domain (TMD) in the YTH screening, followed by testing interactions of the full-length protein in the bimolecular fluorescence complementation (BiFC) and coimmunoprecipitation (co-IP) assays. Our recent study demonstrated that p33 is a selfinteracting protein and that its self-interaction is mediated by the N-terminal helix (Kang et al. 2017). In this work, we examined the ability of p33 to interact with other CTV proteins. By using three independent screening methods, we showed that p33 interacts with three viral proteins, namely, CP, p20, and p23, in vivo and in planta. Further analysis demonstrated that, upon CTV infection, all four proteins were found in the CTV replication factories and the latter structures were among their interaction sites as well. In addition, CP, p20, and p23 were found in the p33-formed membranous structures. Mapping the interaction domain within the p33 protein revealed that an alpha-helix positioned at the $\mathrm{N}$ terminus of $\mathrm{p} 33$ is engaged in the interactions with all three protein partners. A potential role of these protein interactions in virus ability to infect the extended host range is discussed.

\section{RESULTS}

YTH screening reveals potential interactions of $\mathbf{p 3 3}$ with other CTV proteins.

As shown previously, p33 is not required for virus replication yet is involved in many other aspects of CTV infection (Bak and Folimonova 2015; Folimonova 2012; Sun and Folimonova 2019; Tatineni and Dawson 2012; Tatineni et al. 2008, 2011). Therefore, in this work, we mainly focused on testing its interactions with the proteins encoded in the $3^{\prime}$ half of the virus genome that are implicated in diverse viral processes (Dawson et al. 2013). We also included the two papain-like leader proteases L1 and L2, encoded in the 5' region, which, in addition to processing the viral polyproteins produced upon translation of ORFs $1 \mathrm{a}$ and $1 \mathrm{~b}$, also were shown to mediate virus interactions with the plant hosts (Kang et al. 2018; Karasev et al. 1995). The ORFs encoding the L1, L2, p6, HSP70h, p61, CPm, CP, p18, p13, p20, and p23 proteins (Fig. 1) as well as that of a truncated p33 lacking its C-terminal TMD (p33 cloned into the pGADT7 (pAD) and pGBKT7 (pBD) vectors containing the activation and binding domains of the GAL4 transcription factor ( $\mathrm{AD}$ and $\mathrm{BD}$, respectively). Different combinations of a construct expressing p33 $3 \mathrm{TMD}$ in the $\mathrm{pBD}$ background along with a second pAD-based plasmid expressing one of the CTV proteins were cotransformed into the yeast cells (Fig. 2). The transformed cells grew on the synthetically defined (SD) double drop-out medium (DDO), indicating that both plasmids were successfully cotransformed and the synthesis of leucine and tryptophan was complemented by the introduced $\mathrm{pAD}$ and $\mathrm{pBD}$ plasmids, respectively. To test for the interactions of the recombinant proteins, the cotransformed yeasts were subsequently grown on SD media with the increasing stringencies: DDO without histidine (triple drop-out [TDO]) and TDO without adenine (quadruple drop-out [QDO]). Yeast cells cotransformed with a pair of positive control plasmids (pAD-T and pBD-53) grew well on both TDO and QDO, indicating the activation of the reporter genes generating histidine and adenine, which was mediated by the interaction of proteins expressed from the cloned genes in the $\mathrm{pAD}$ and $\mathrm{pBD}$ plasmids.

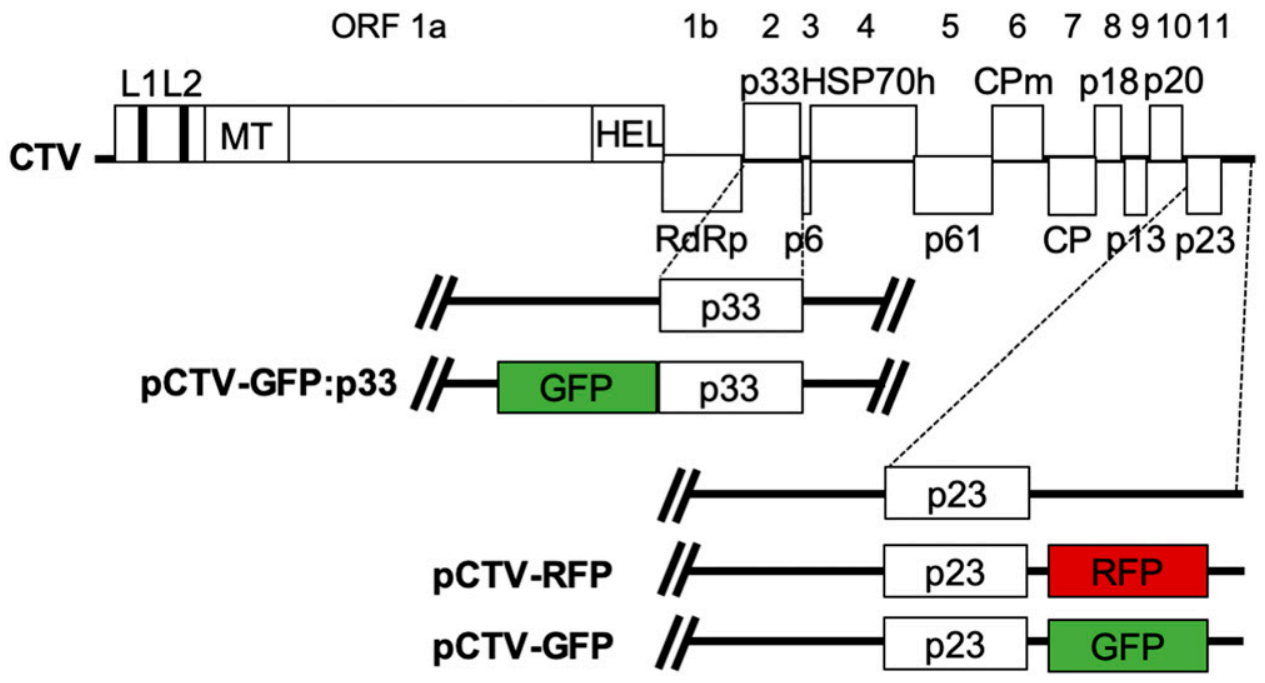

Fig. 1. Schematic representation of the citrus tristeza virus (CTV) genome and its derivatives used in this study. Open reading frames (ORFs) and their translated products are represented as boxes. L1 and L2, papain-like protease domains; MT, methyltransferase; HEL, helicase; RdRp, RNA-dependent RNA polymerase; HSP70h, HSP70 homolog; CPm, minor coat protein; CP, coat protein. The three CTV derivatives are shown under the enlarged genome segments. pCTV-RFP and pCTV-GFP have the red or green fluorescent protein ORFs (RFP or GFP, respectively) inserted between the p23 ORF and the 3 ' nontranslated region. Their expression is driven by the CTV CP subgenomic RNA promoter. pCTV-GFP:p33 has the GFP ORF fused to the $5^{\prime}$ end of the p33 ORF. 
On the other hand, yeast cells cotransformed with a pair of negative control plasmids (pAD-T and pBD-Lam) did not grow on either TDO or QDO, indicating that the expressed proteins did not interact. Furthermore, yeast cells cotransformed with pBD-p33 $\Delta$ TMD and pAD-p33 $\Delta$ TMD showed growth on both TDO and QDO, which correlated with the results reported earlier (Kang et al. 2017). The interaction strength between the recombinant proteins was evaluated based on the stringency of the media on which the tested cotransformed yeasts could grow. The interaction was considered moderate if the transformed yeast cells grew on TDO but not on QDO. The interaction was considered strong if the transformed yeast cells grew on both TDO and QDO. As shown in Figure 2, p33 3 TMD did not show interaction with the L1, L2, p6, HSP70h, or p61 proteins. On the other hand, strong interactions were detected between $\mathrm{p} 33 \Delta \mathrm{TMD}$ and $\mathrm{p} 13$, $\mathrm{p} 20$, and $\mathrm{p} 23$. The remaining three proteins - $\mathrm{CPm}, \mathrm{CP}$, and p18 - showed moderate interactions with p33 $\triangle$ TMD. The reciprocal combinations using pAD-p33 $\triangle \mathrm{TMD}$ and $\mathrm{pBD}$ plasmids expressing other proteins gave similar results (data not shown).

\section{BiFC and co-IP analyses confirm interactions of p33 with p20, p23, and CP.}

To validate the YTH results and examine interactions between CTV proteins in planta, BiFC and co-IP tests were conducted. For BiFC experiments, a full-length p33 ORF and the ORFs of CPm, CP, p18, p13, p20, and p23 were fused to the coding regions of the $\mathrm{N}$-terminal (amino acid [aa] residues 1 to 174 [nEYFP]) or C-terminal (aa residues 175 to 239 [cEYFP]) parts of the enhanced yellow fluorescent protein (EYFP) in the binary vectors, allowing transient expression of these recombinant proteins in leaves of Nicotiana benthamiana via agroinfiltration. The ability of p33 expressed as a fusion with one of the EYFP halves to interact with another protein partner fused to the second EYFP half was determined based on reconstruction of the functional EYFP resulting in detectable fluorescence. As shown in Figure 3A, the p33 protein was able to interact with three partners, i.e., CP, p20, and p23. However, no interaction was detected between $\mathrm{p} 33$ and CPm, p13, or p18, using the BiFC approach (Fig. 3A). To exclude a possibility that lack of p33 interaction with the latter proteins was due to the absence of their expression upon agroinfiltration-mediated delivery of the respective constructs, we conducted a Western blot analysis using the protein extracts obtained from the agroinfiltrated plants and the antibody against cEYFP, which was used to tag those proteins in the BiFC assay. As shown in Supplementary Figure S1, the proteins were expressed at the level of another partner (e.g., cEYFP:p20) that was able to interact with $\mathrm{p} 33$.

Unlike p33 self-interacting complexes, which were detected primarily on the plasma membrane and in a few small intracellular vesicles (Fig. 3A, left panel in the top row, yellow and white arrowheads), the p33-CP and p33-p23 complexes were seen as aggregates in the cytoplasm that varied in size as well as punctate accumulations along the plasma membrane (Fig. 3A, left and right panels in the middle and bottom rows, yellow arrowheads point to the accumulations on the plasma membrane). On the other hand, the interaction between the p33 and p20 proteins was observed in a form of fewer cytoplasmic aggregations (Fig. 3A, central panels in the middle and bottom rows).

The co-IP experiments confirmed the interaction between p33 fused to a green fluorescent protein (GFP) with the CP, p20, and 23 proteins. In these tests, each of the three latter proteins

\begin{tabular}{|c|c|c|c|c|c|}
\hline \multirow{2}{*}{$\mathrm{pAD}$} & \multirow{2}{*}{$\mathrm{pBD}$} & \multicolumn{3}{|c|}{ Yeast growth } & \multirow{2}{*}{ Interaction } \\
\hline & & DDO & TDO & QDO & \\
\hline $\mathrm{T}$ & 53 & +9 & 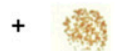 & + 的 & Strong \\
\hline$T$ & Lam & $+\theta$ & - & - & No Interaction \\
\hline $\mathrm{p} 33 \Delta \mathrm{TMD}$ & $\mathrm{p} 33 \Delta \mathrm{TMD}$ & +6 & $+\frac{6}{6}$ & $+\quad$ & Strong \\
\hline L1 & $\mathrm{p} 33 \Delta \mathrm{TMD}$ & +0 & - & - & No Interaction \\
\hline L2 & $\mathrm{p} 33 \Delta \mathrm{TMD}$ & $+\infty$ & - & - & No Interaction \\
\hline p6 & $\mathrm{p} 33 \Delta \mathrm{TMD}$ & +9 & - & - & No Interaction \\
\hline HSP7Oh & $\mathrm{p} 33 \Delta \mathrm{TMD}$ & +1 & - & - & No Interaction \\
\hline p61 & $\mathrm{p} 33 \Delta \mathrm{TMD}$ & $+\infty$ & - & - & No Interaction \\
\hline $\mathrm{CPm}$ & p33 $\triangle \mathrm{TMD}$ & + & $+2 x_{k}$ & - & Moderate \\
\hline $\mathrm{CP}$ & p33 $\triangle \mathrm{TMD}$ & +8 & +3 & - & Moderate \\
\hline $\mathrm{p} 18$ & $\mathrm{p} 33 \Delta \mathrm{TMD}$ & +8 & $+\quad 3$ & - & Moderate \\
\hline $\mathrm{p} 13$ & $\mathrm{p} 33 \Delta \mathrm{TMD}$ & +6 & + & + और & Strong \\
\hline p20 & p33 $\Delta$ TMD & +8 & + & + dy & Strong \\
\hline $\mathrm{p} 23$ & $\mathrm{p} 33 \Delta \mathrm{TMD}$ & + & + & + & Strong \\
\hline
\end{tabular}

Fig. 2. Summary of yeast two-hybrid screening using citrus tristeza virus (CTV) proteins. Saccharomyces cerevisiae Y2HGold was cotransformed with a gene of p33 lacking the transmembrane domain (TMD) and other CTV genes cloned into pGBKT7 (pBD) and pGADT7 (pAD) plasmids, respectively, and grown on selective agar media to assess the activation of reporter genes (drop-out media [DDO], synthetically defined [SD]/-Leu-Trp; TDO, SD/-Leu-Trp-His; QDO, SD/-Leu-Trp-His-Ade). pAD-T, pBD-53, and pBD-Lam supplied by the manufacturer were used as controls. T, 53, and Lam are SV40 large T-antigen, murine p53, and lamin, respectively. The cell growth on DDO media indicates cotransformation of both plasmids. In the yeast growth column, a plus $(+)$ represents cell growth on the corresponding medium and a minus (-) represents no cell growth on the corresponding medium. The image showing cell growth for each cotransformed yeast cell is shown next to + . Results are representative of three independently repeated experiments. 
was fused with the red fluorescent protein (RFP) and was coexpressed with the GFP-tagged $\mathrm{p} 33$ in the $N$. benthamiana leaves. Free RFP was used as a negative control. Protein extracts obtained from these leaves were subjected to co-IP, using the anti-GFP antibody followed by the immunoblot analysis. All the above three proteins were detected in the eluted fractions, confirming their ability to interact with the $\mathrm{p} 33$ protein in vivo and in planta. No interaction was detected between GFP: p33 and RFP in the control treatment (Fig. 3B).

\section{Upon coexpression, p33 and its interacting protein} partners localize in the same cellular compartments.

To further analyze the relationships between p33 and the other three viral proteins, we examined the subcellular localization of the $\mathrm{CP}, \mathrm{p} 20$, and p23 proteins when those were expressed individually or in the presence of $\mathrm{p} 33$. For microscopy

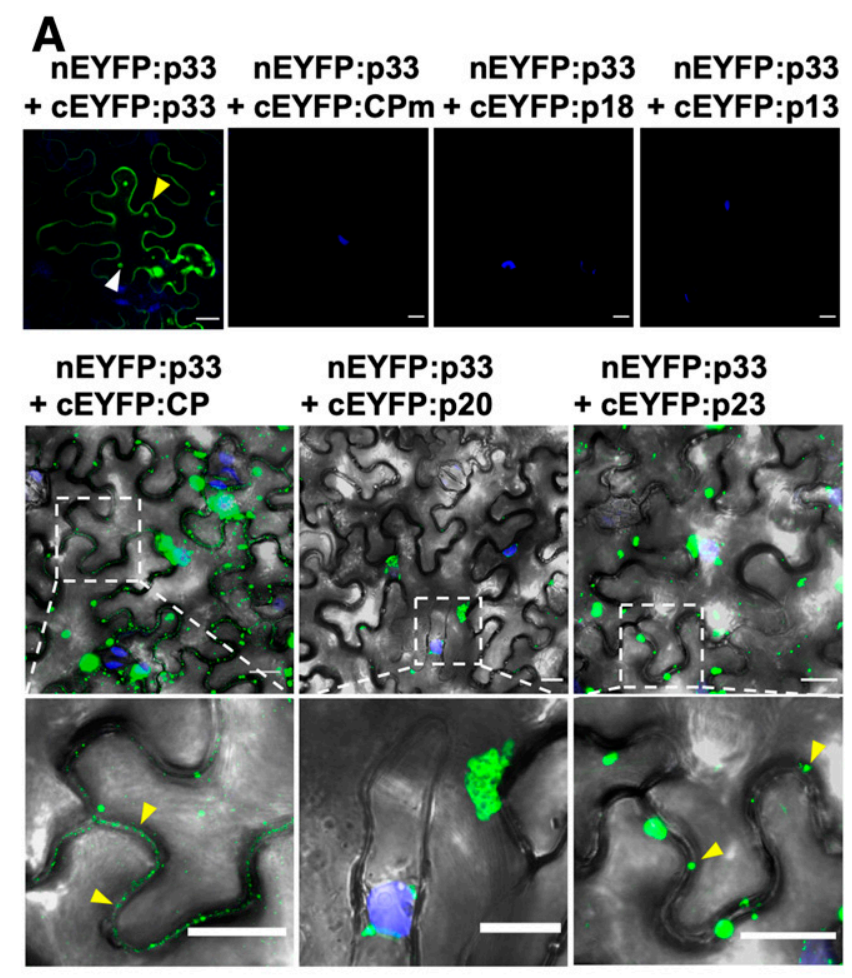

B

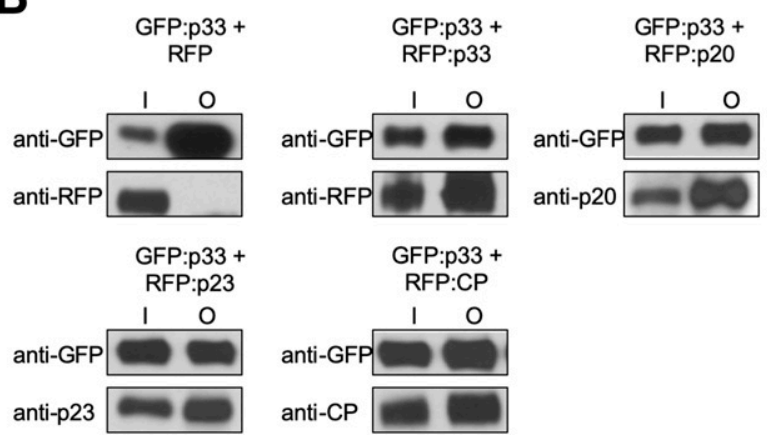

Fig. 3. Interaction of p33 and its partners. A, Maximum projection images of Nicotiana benthamiana leaves, infiltrated with the corresponding constructs, obtained using a confocal microscope. Photos were taken at $4 \mathrm{dpi}$. Nuclei were marked with cyan fluorescent protein targeted to the nucleus. White or yellow arrowheads point to enhanced yellow fluorescent protein (EYFP) signal in a vesicle or along the plasma membrane, respectively. Bar = $20 \mu \mathrm{m}$. B, Western blot analysis of proteins extracted from $N$. benthamiana leaves expressing the respective proteins before $(\mathrm{I}=$ input) or after coimmunoprecipitation using anti-green fluorescent protein antibody-conjugated agarose beads $(\mathrm{O}=$ output). observations, the proteins were expressed as the GFP or RFP fusions, and the respective constructs were introduced in the leaves of $N$. benthamiana plants via agroinfiltration. As shown in Figure 4A, upon individual expression, the intracellular distribution of the above proteins tagged with GFP or RFP was very different from the typical distribution of the untagged GFP or RFP proteins. The $\mathrm{p} 33$ protein formed punctate accumulations along the cellular membrane and was also seen in the cytoplasmic vesicles (Fig. 4A, left bottom row), which resembled findings of our earlier work (Bak and Folimonova 2015). The CP was found in the numerous small bodies located throughout the cytoplasm and in proximity to the plasma membrane (Fig. 4A, top row on the right side). The p20 protein was found forming few aggregates in the cytoplasm and, additionally, was detected in the nucleus (Fig. 4A, middle row on the right side), similar to what has been reported previously (Gowda et al. 2000). p23 was visualized in the punctate structures along the plasma membrane, in aggregations in the cytoplasm, and also in the nucleus (Fig. 4A, bottom row on the right side). These observations corresponded to those in an earlier study showing the p23 protein of CTV at the plasmodesmata and in the Cajal bodies (Ruiz-Ruiz et al. 2013).

At the next step, p33 was coexpressed in pairs with the three interacting partners. In these experiments, no obvious colocalization of all the p33 protein-labeled structures and the $\mathrm{CP}$ was observed, yet both proteins appeared in the association with each other at certain spots on the cellular membrane (Fig. $4 \mathrm{~B}$, top row, white arrows). Furthermore, the p20 inclusions were found to be surrounded by or embedded in the net-like structures formed by $\mathrm{p} 33$ in the cytoplasm (Fig. 4B, middle row, white arrow). Both p33 and p23 were seen colocalizing at a number of spots on the plasma membrane as well as in a few vesicle-like structures (Fig. 4B, bottom row, white arrows).

To complement microscopy observations, we performed differential centrifugation of the protein extracts produced from the plant tissues infiltrated with the respective expression cassettes coupled with immunoblotting (Fig. 4C). Upon individual expression, $\mathrm{CP}$ was detected primarily in the S30 fraction containing soluble proteins, yet a small portion was found in the P3 pellet that comprises the larger and denser structures, like nuclei and inclusion bodies and the P30 pellet representing a crude membrane fraction. The p20 protein was found exclusively in P3, which correlated with the results of the microscopy observations. The p23 protein was split between the P3 pellet and the S30 supernatant. Neither p20 nor p23 were found in the membrane-containing P30 fraction. On the other hand, similarly to what we found previously (Kang et al. 2015), a large proportion of $\mathrm{p} 33$, which possesses a TMD, precipitated in the P30 pellet. When $\mathrm{p} 33$ was coexpressed with each of the above three proteins, p20 and p23 showed a change in their localization and some proportion of them was detected in the membrane fraction along with p33 (Fig. 4C, asterisks). This appeared to be in the agreement with the detection of both p20 and $\mathrm{p} 23$ in the p33-formed membranous structures, suggesting that the interaction of p33 with these two proteins affected localization of the former proteins. Coexpression of $\mathrm{p} 33 \mathrm{did}$ not alter $\mathrm{CP}$ distribution, and $\mathrm{CP}$ remained in the membrane $\mathrm{P} 30$ fraction along with being present in other fractions, similar to what was observed upon its individual expression.

\section{Intracellular localization of the interacting protein} partners in the context of viral infection.

Next, we examined the intracellular distribution of p33, p20, p23, and CP in the context of CTV infection by overexpressing each of the above proteins labeled with a fluorescent protein tag along with a construct containing a cDNA of the viral genome modified to carry an extra ORF of the GFP or RFP, pCTV-GFP 
A
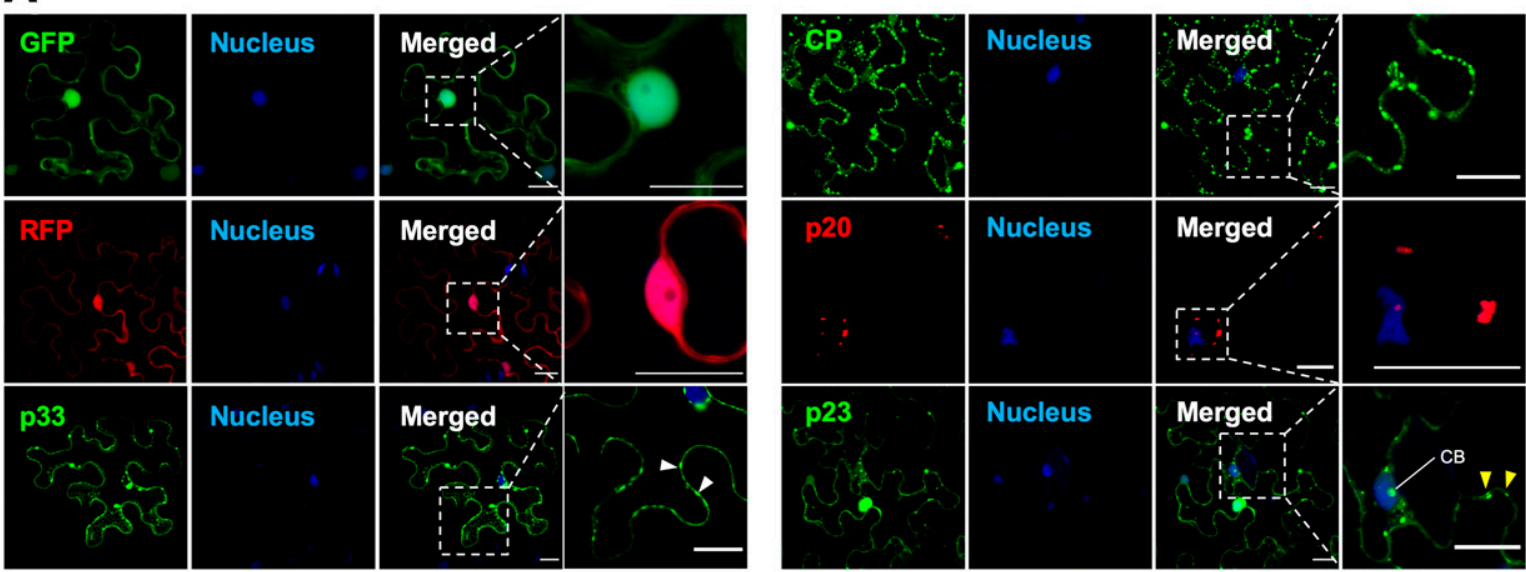

B
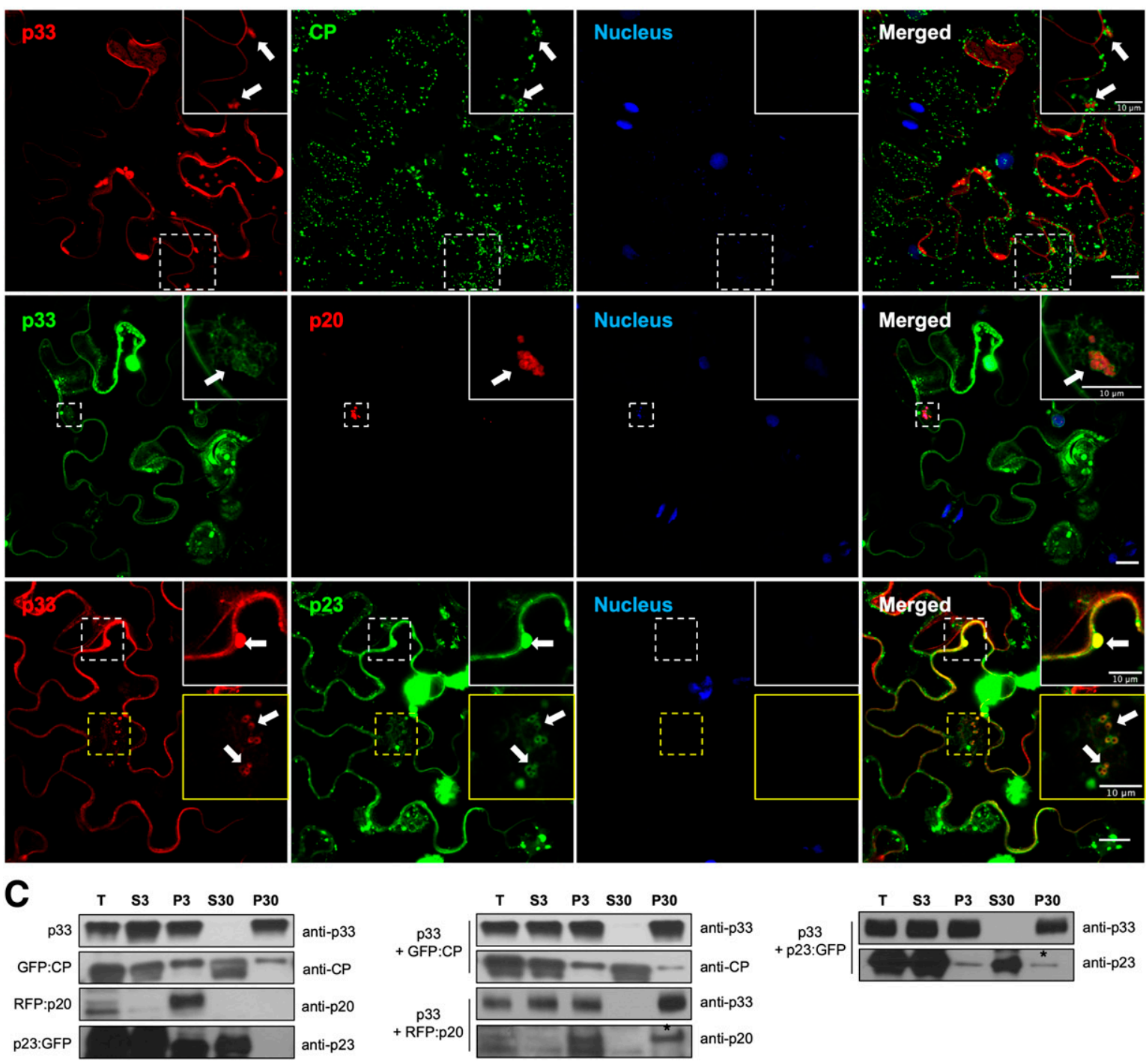

Fig. 4. Intracellular localization of $\mathrm{p} 33$ and its interacting partners. A and $\mathbf{B}$, Images from maximum projections of Nicotiana benthamiana leaves infiltrated with the corresponding constructs, except for zoomed-in images corresponding to the dotted squares, which represent single sections. Photos were taken at 4 days postinfiltration. Nuclei were marked with cyan fluorescent protein targeted to the nucleus. Digital color signal in each panel was assigned according to the fluorescent protein used to tag the target protein (RFP designated in red, GFP in green, and CFP in blue). White and yellow arrowheads point at the p33 and p23 accumulations at the plasma membrane, respectively. Thick white arrows indicate areas in the cells where p33 and its partners are co-present. CB $=$ Cajal bodies. Bar $=20 \mu \mathrm{m}$, unless otherwise noted. C, Subcellular fractionation of protein extracts from $N$. benthamiana leaves infiltrated with the constructs expressing the citrus tristeza virus proteins. $\mathrm{T}=$ total protein extract; $\mathrm{S} 3=$ supernatant obtained from centrifugation at $3,000 \times g ; \mathrm{P} 3=$ pellet from centrifugation at $3,000 \times g ; \mathrm{S} 30=$ supernatant from centrifugation at $30,000 \times g ; \mathrm{P} 30=$ pellet from centrifugation at $30,000 \times g$. Viral proteins in the subcellular fractions were detected using Western blotting with the respective antibodies. An asterisk (*) indicates RFP:p20 or GFP:p23 precipitated in P30, a membrane-enriched fraction. 
and pCTV-RFP (Fig. 1) (Bergua et al. 2014; El-Mohtar and Dawson 2014). Cells expressing the latter virus constructs exhibited formation of large, dense, cytoplasmic masses, which retained the fluorescent protein and were adjacent to the nucleus (Fig. 5A, middle row, white arrowhead). These structures were not present in cells of the control tissue samples infiltrated with a plasmid driving expression of the RFP protein only, which was evenly distributed throughout the cytoplasm and the nucleus (Fig. 5A, top row, yellow arrowhead). Previously, similar perinuclear bodies have been observed with other plant viruses upon their infection of plant cells and were identified as viral replication complexes (VRCs) (Barton et al. 2017). To determine whether the large aggregations observed here were CTV VRCs, CTV-RFP was coexpressed with a GFP-fused flock house virus (FHV) protein B2, which binds to the doublestranded RNA and, thus, is expected to label viral replication intermediates present in the viral factories (Monsion et al. 2018). GFP:B2 was seen diffused throughout the cytoplasm and concentrated in the nucleus (Fig. 5A, bottom row, yellow arrowhead) when no CTV was introduced. In contrast, in the presence of CTV-RFP, a profound change in the B2 localization was noted; GFP:B2 redistributed from the nucleus to the dense structure adjacent to the latter and was completely omitted from the nucleus (Fig. 5A', white arrowhead points to the B2 accumulation). This observation resembled findings with a number of plant viruses reporting formation of replication factories in the vicinity of the nucleus and the association of the $\mathrm{B} 2$ protein with them (Monsion et al. 2018).

Expression of each of the four viral proteins together with the virus cassette revealed that all were associated with the VRCs (Fig. 5B). Most of p33, p23, and some of the $\mathrm{CP}$ were distributed throughout the whole VRC structures. The $\mathrm{p} 33$ protein had a vesicular appearance, with some vesicles dispensing beyond the central part of the VRC into the cytoplasmic areas adjacent to the cellular membrane (Fig. 5B, top row). The p20 protein was seen as small inclusions scattered irregularly throughout the replication sites (Fig. 5B, third row). In contrast, coexpression of an unrelated protein-a mitochondrial marker, the N-terminal fragment of isovaleryl-CoA dehydrogenase fused to RFP (Block et al. 2014), used here as a negative control-and CTV-GFP resulted in a lack of association of this RFP-tagged protein with the CTV VRCs (Supplementary Fig. $\mathrm{S} 2$ ), confirming that the presence of a fluorescent proteinlabeled p33, CP, p20, and p23 in the VRCs was specific.

The above experiment examined the intracellular distribution of the CP, p20, and p23 proteins upon replication of the wildtype full-length CTV, which drives production of the $\mathrm{p} 33$ protein in the infected cells. In order to assess whether the presence of these proteins in the VRCs was a result of their recruitment by $\mathrm{p} 33$, we performed coexpression of each of the three proteins with the CTV p33 deletion mutant (CTV- RFP: $\Delta$ p33 or CTV-GFP:Ap33) (Bergua et al. 2014; Sun and Folimonova 2019). In the absence of $\mathrm{p} 33$ production, $\mathrm{CP}, \mathrm{p} 20$, and $\mathrm{p} 23$ were found localizing in the VRCs, similar to what we observed upon their coexpression with the full-length CTV (Supplementary Fig. S3). This suggested that their presence in the VRCs was not a result of the p33-mediated targeting.

Next, we looked at the localization of the protein interaction sites in the presence of the virus. To this end, CTV-RFP and nEYFP:p33 were coexpressed along with cEYFP:p20, cEYFP: p23, or cEYFP:CP. As shown in Figure 6A, a strong signal of the reconstructed EYFP was detected upon coexpression of nEYFP:p33 with each of the three proteins fused with cEYFP. In all cases, the EYFP signal was observed within the dense egg-shaped masses adjacent to the nucleus (Fig. 6A, white arrowheads), which were previously identified as the sites of virus replication (Fig. 5). While the VRCs appeared to be the most prominent sites of the p33 interaction with both the p20 and $\mathrm{p} 23$ proteins, the interaction between $\mathrm{CP}$ and $\mathrm{p} 33$ was also detected in multiple additional locations throughout the cytoplasm and in the vicinity of the cellular membrane (Fig. 6A).

To assess the intracellular localization of the interacting partners upon virus infection, we took advantage of a CTV construct in which the p33 ORF was fused with that of GFP (Fig. 1, pCTVGFP:p33) (Kang et al. 2015). CTV-GFP:p33 was coexpressed with the RFP-tagged CP, p20, or p23 proteins. Similar to the observations above, p33 was found in the association with the latter three proteins (Fig. 6B, white arrows). p33 and CP were colocalizing in the structures resembling viral replication bodies as well as in small aggregations on the plasma membrane and vesicle-like structures (Fig. 6B, first and second rows). p20 was seen enclosed in the structures formed by $\mathrm{p} 33$, and the two proteins were also present in the VRC-like aggregations adjacent to the nucleus (Fig. 6B, third and fourth rows). Similarly, both p33 and p23 accumulated in the VRCs (Fig. 6B, fifth row). These observations pointed out that $\mathrm{p} 33$ and its protein partners localize, interact, and likely function together in a number of cellular sites, including CTV replication factories.

\section{The N-terminal helix of p33 is required and is sufficient for its interaction with all three protein partners.}

The computational analysis of the p33 aa sequences, using PSIPRED Protein Analysis Workbench (Buchan et al. 2013), predicted two alpha helices located at the $\mathrm{N}$ - and $\mathrm{C}$-terminal ends of the protein (Fig. 7A). The C-terminal helix comprises a TMD (aa residues 279 to 299) and appears to be dispensable for the p33 interaction with the three viral proteins, as those were detected in our experiments with the truncated TMD-lacking p33 in the YTH approach (Fig. 2). As we showed earlier, the Nterminal helix spanning aa residues 10 to 30 is involved in selfinteraction of p33 (Kang et al. 2017). In order to examine whether this region participates in the interactions between $\mathrm{p} 33$ and the $\mathrm{CP}, \mathrm{p} 20$, and $\mathrm{p} 23$ proteins, we tested the interaction of a p33 mutant containing a deletion of the $\mathrm{N}$-terminal 30-aa residues $(\mathrm{p} 33 \Delta \mathrm{N} 30)$ with the other three proteins, using BiFC. As shown in Figure $7 \mathrm{~B}$, the truncated p33 mutant fused with the N-terminal half of the EYFP (nEYFP:p33 $\Delta$ N30) was unable to interact with any of the three CTV proteins fused with the C-terminal half of EYFP, yet the expression of nEYFP: p33 3 N30 upon agroinfiltration-mediated introduction of the respective construct was confirmed via Western blotting with the antibody against nEYFP (Supplementary Fig. S4). To assess whether the N-terminal helix is sufficient for p33 interaction with those proteins, we examined the results of coexpression of the nEYFP fusion with a peptide comprising the first 30 aa residues in the $\mathrm{p} 33$ protein sequence (nEYFP:p33N30) with the respective proteins fused to the cEYFP domain. As demonstrated in Figure 7B, coexpression of cEYFP:p20, cEYFP:p23, or cEYFP:CP along with nEYFP:N30 resulted in the restoration of EYFP fluorescence, in contrast to the control treatments, in which no EYFP fluorescence was observed upon coexpression of the three former fusion proteins with nEYFP (Fig. 7B, a to e). This suggests that, in addition to its role in the p33 protein selfinteraction, the N-terminal helix is responsible for the p33 interactions with the other viral proteins.

\section{DISCUSSION}

Examination of a viral protein interactome is one approach to gain insight into how proteins encoded by a virus mediate its host infection. With a complex CTV-citrus pathosystem that combines one of the largest plant RNA viruses and a long-living perennial woody host, obtaining such understanding appears 
particularly challenging. To date, our knowledge on the interactions of CTV proteins has been, essentially, limited to the observed self-interaction of several viral proteins-the RdRp, p33, CP, p20, and p23 (Çevik 2013; Gowda et al. 2000; Kang et al. 2017; Nchongboh et al. 2014; Ruiz-Ruiz et al. 2018). In this study, we extended this knowledge by revealing a number of interactions between heterologous virus proteins. We demonstrated that $\mathrm{p} 33$, a unique nonconserved protein of CTV
A

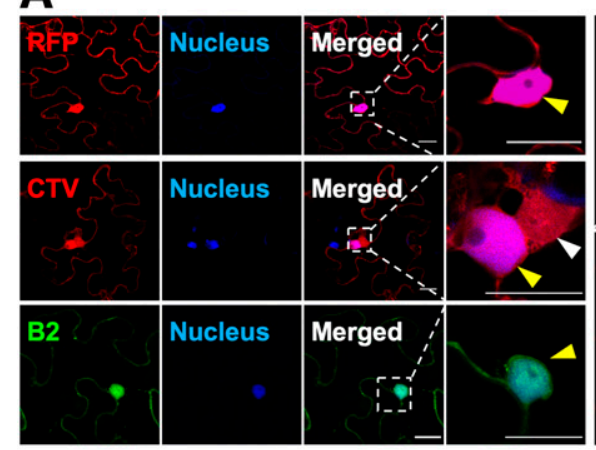

A'
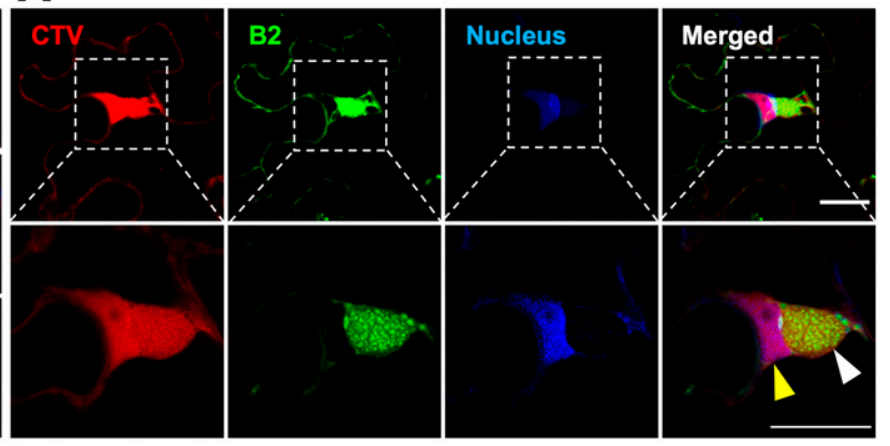

B

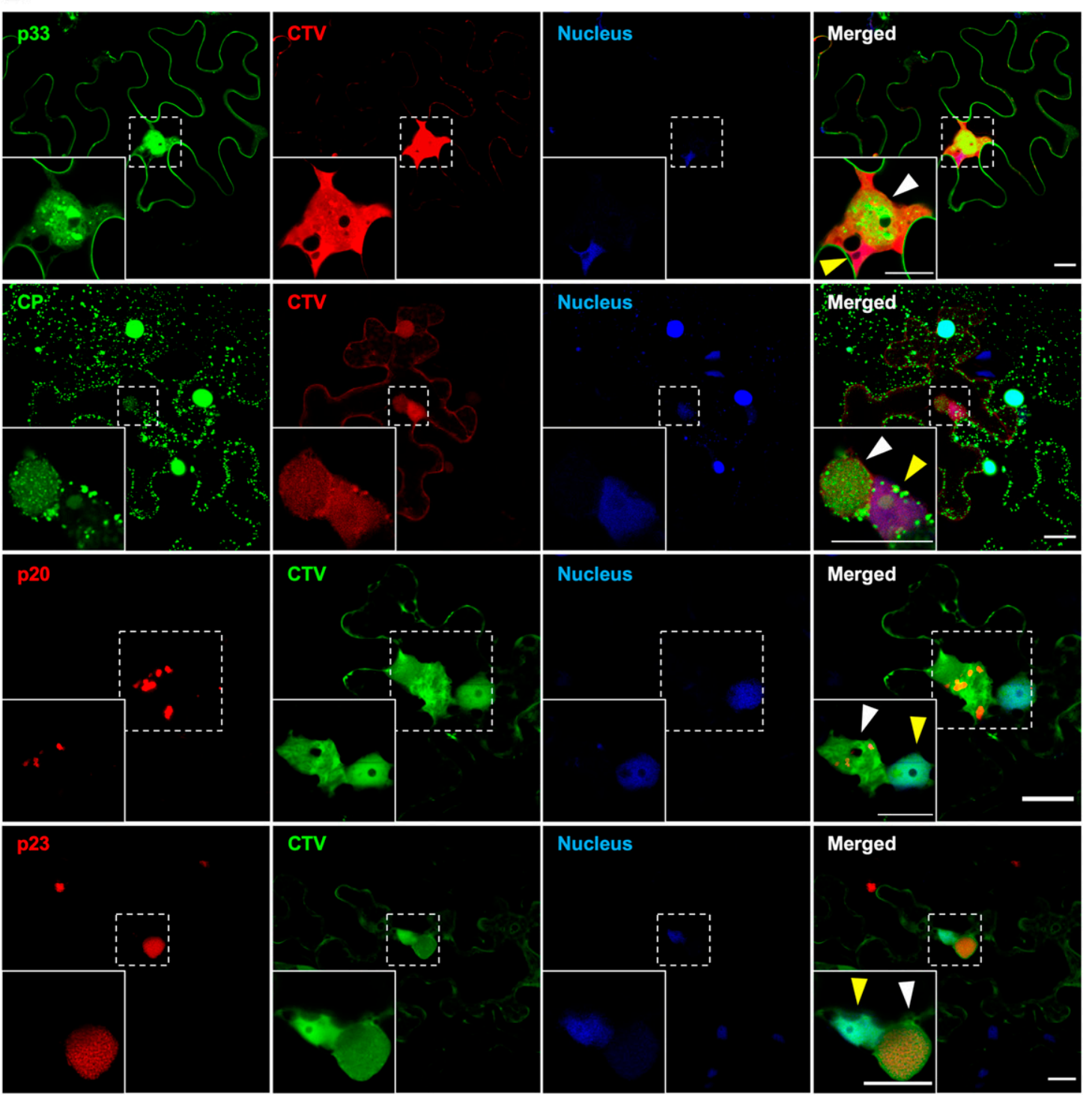

Fig. 5. Intracellular localization of $\mathrm{p} 33$ and its protein partners in the presence of citrus tristeza virus (CTV). A and A', Fluorescent protein-labeled structures visualized upon expression of free red fluorescent protein (RFP), CTV, and flock house virus B2. B, Subcellular localization of p33, p20, p23, and coat protein (CP) relative to CTV viral replication complexes (VRCs). Plasmid constructs expressing GFP:p33 and GFP:CP were co-agroinfiltrated along with a CTVRFP-expressing construct, and plasmid constructs expressing RFP:p20 and RFP:p23 were co-agroinfiltrated along with pCTV-GFP. All images are from maximum projections of infiltrated Nicotiana benthamiana leaves, except for zoomed-in images corresponding to the dotted squares, which represent single sections. Photos were taken at 5 days postinfiltration. Nuclei were marked with cyan fluorescent protein targeted to the nucleus. Yellow arrowheads point to nuclei; white arrowheads to VRCs; dotted squares correspond to zoomed-in areas. Bar $=20 \mu \mathrm{m}$. 


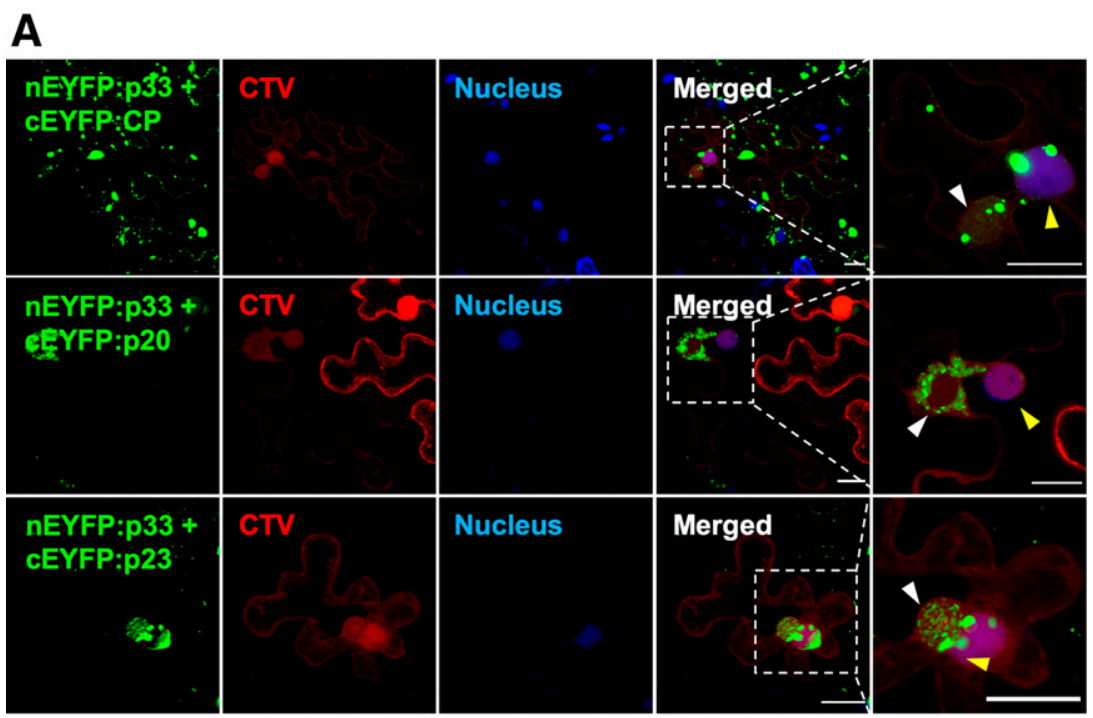

B

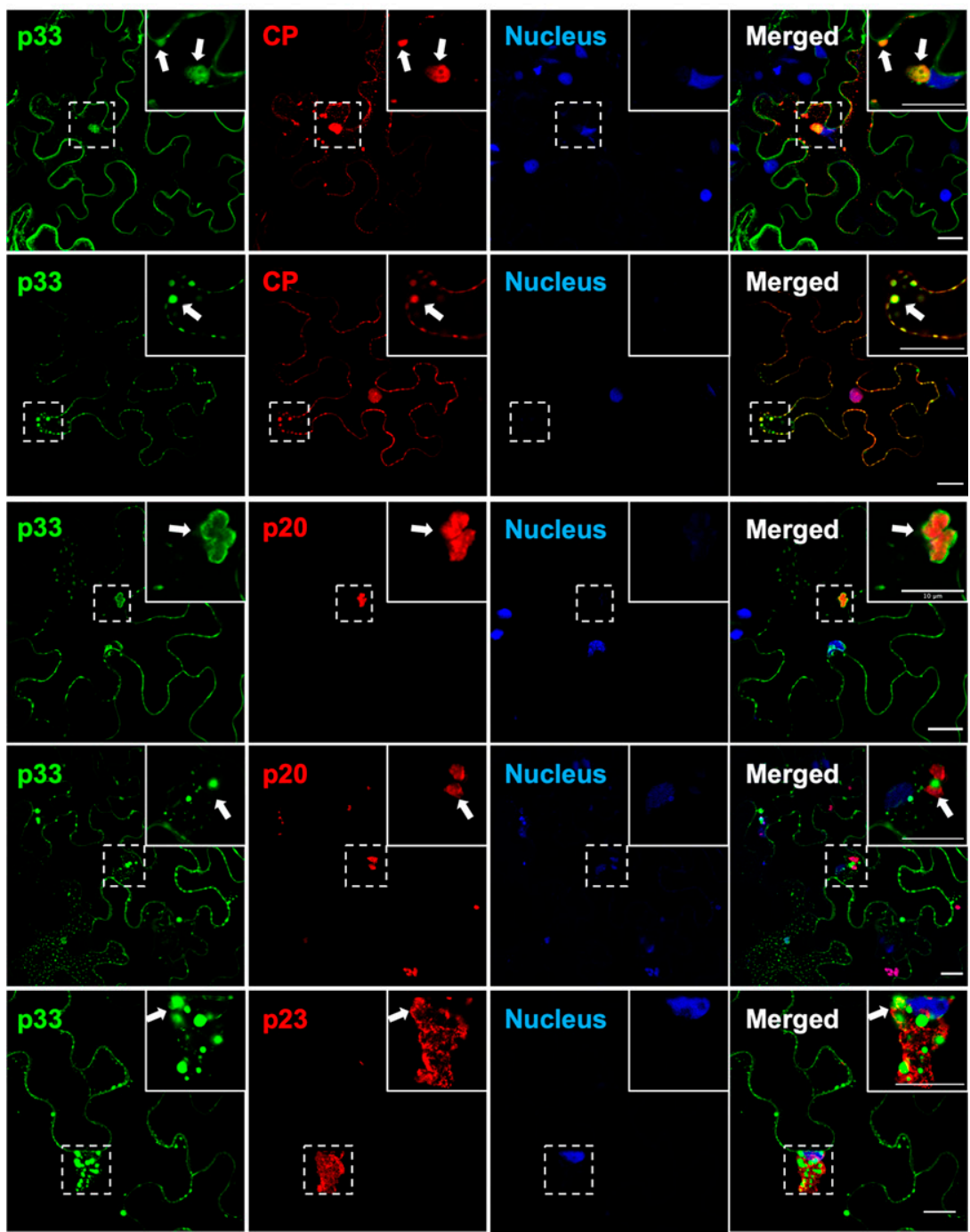

Fig. 6. Interaction sites and subcellular localizations of p33 and its partner proteins in the presence of citrus tristeza virus (CTV). A, Nicotiana benthamiana cells expressing CTV-RFP (red fluorescent protein) and N-terminal enhanced yellow protein expressed in p33 (nEYFP:p33) along with either C-terminal cEYFP:CP, cEYFP:p20, or cEYFP:p23. Yellow arrowheads point to nuclei; white arrowheads to viral replication complexes. B, N. benthamiana cells expressing pCTV-GFP:p33 with RFP:CP, RFP:p20, or RFP:p23. All images are from maximum projections of infiltrated $N$. benthamiana leaves, except for zoomed-in images corresponding to the dotted squares, which represent single sections. Photos were taken at 5 days postinfiltration. Nuclei were marked with cyan fluorescent protein targeted to the nucleus. Thick white arrows indicate areas in the cells in which p33 and its partners are co-found. Bar $=20 \mu \mathrm{m}$, unless otherwise noted. 
shown to participate in many different viral processes, interacts with multiple protein partners. Among those, p33 interactions with the CP, p20, and p23 was confirmed by three independent screening methods, i.e., YTH, co-IP, and BiFC. Interestingly, unlike the latter three proteins, which are absolutely required for virus accumulation and systemic spread in all citrus hosts, p33 appears dispensable for infection of at least several varieties of citrus (Tatineni et al. 2008). With that in mind, the protein is needed for virus ability to infect a few others, such as sour orange and lemon, which led to the hypothesis that p33 mediates specific interactions with individual hosts (Tatineni et al. 2011). This hypothesis is supported by recent findings that the $\mathrm{p} 33$ protein functions as a nonconserved movement protein (Bak and Folimonova 2015) and, furthermore, that it interacts with plant immunity (Sun and Folimonova 2019). In addition, p33 plays a crucial role in the ability of a CTV variant to protect the host it occupies from superinfection by a second closely related virus variant (Folimonova 2012). On the other hand, the three interacting partners of $\mathrm{p} 33$ are essential for CTV infection in all host plants and have important functions in the virus cycle. The $\mathrm{CP}$ is involved in virion assembly and virus translocation (Agranovsky et al. 1995; Tian et al. 1999), while p23 controls asymmetrical accumulation of the positive- and negativestranded RNAs during viral replication (Satyanarayana et al. 2000, 2002). Most interestingly, together with p20, these proteins are also viral suppressors of RNA silencing, the major antiviral mechanism in plants (Lu et al. 2004). It seems remarkable that p33, which, as discussed above, mediates infection of certain citrus hosts, interacts with all three proteins sharing a common role in modulating host defense response to virus infection. Importantly, the hosts requiring p33 (i.e., sour orange and lemon) show minimal susceptibility, even with the full-length wild-type virus, while they resist infection with a p33 gene-deletion mutant (Tatineni et al. 2011). It could be hypothesized that, in the process of mediating CTV infection in those hosts, the $\mathrm{p} 33$ protein functions through interaction with its viral partners involved in mitigation of the immune host response.

Examination of the cellular protein interaction sites and coexpression analyses showed that all four proteins were present in the CTV replication factories and the latter structures appeared to be their interaction sites as well. The localization of p20, p23, and CP within those VRCs correlates well with their roles in replication, protection against degradation, and assembly of viral RNA genomes. As p33 is dispensable for virus replication, its presence in the VRCs suggests that those could be the sites where the protein is being produced or where it forms interaction complexes with other viral proteins. It is wellaccepted that many processes of the positive-stranded RNA virus cycle are coupled to replication, including viral RNA translation as well as virus encapsidation and movement (Saxena and Lomonossoff 2014). In many studies, viral proteins that are not required for replication were found in the replication complexes (Linnik et al. 2013; Lõhmus et al. 2016). Similarly, CP, p20, p23, and p33 were found in the CTV VRCs in our work. In addition, CP, p20, and p23 were detected in the p33-formed cytoplasmic membranous structures (i.e., vesiclelike structures). As we showed earlier, p33 vesicles traffic via the cellular endomembrane system (Bak and Folimonova, 2015). It seems plausible that $\mathrm{p} 33$ provides a membrane scaffold for the other viral proteins to anchor to or mediates their intracellular transport to specific locations or both as well as creates protective subcellular compartments isolated from the host cytoplasm, thus, strengthening or modulating the performance of these viral proteins. This proposition is in the agreement with an earlier demonstration that elevation of the ability of CTV to counteract host RNA silencing by overexpression of a viral silencing suppressor resulted in a significant increase in the level of virus accumulation in sour orange, a host requiring p33 for successful virus infection (Fagoaga et al. 2011).

The finding that p33 interacts with several viral partners suggests that those interactions might be transient. This also correlates with the results of mapping the p33 protein binding domain.

Remarkably, the N-terminal helix of p33 was found to be required and sufficient for the interaction with all three proteins, i.e., CP, p20, and p23. In addition, as we showed earlier, the same protein region mediates self-interaction of $\mathrm{p} 33$. Therefore, it appears that this part of the $\mathrm{p} 33$ protein is engaged in multiple protein-protein interactions, suggesting a likelihood that those interactions take place at different timepoints or sites.

In summary, this study demonstrates that a nonconserved p33 protein of CTV, which confers virus ability to infect the

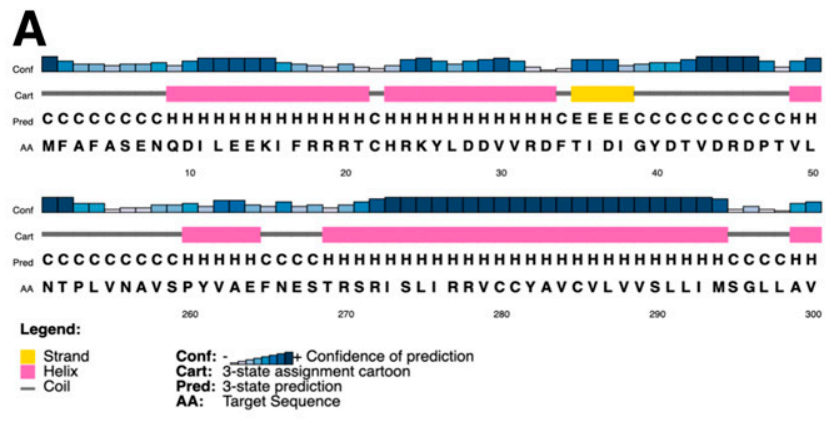

B
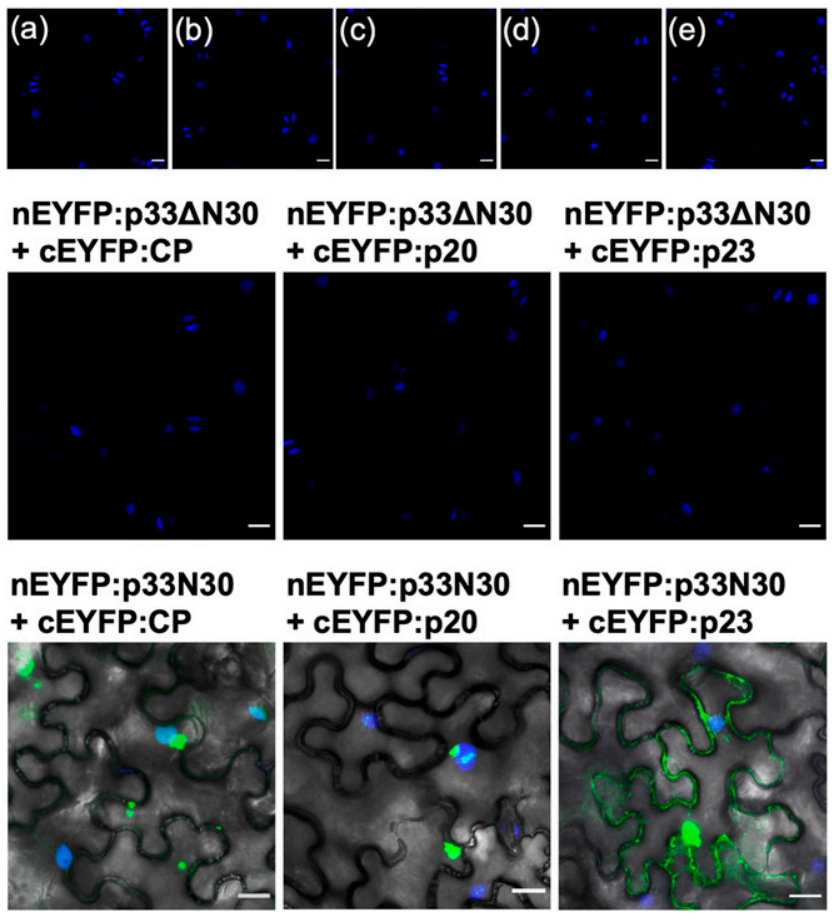

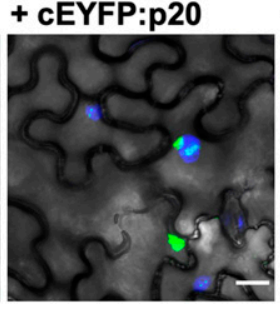

Fig. 7. Mapping the domain of p33 responsible for interactions with p20, p23, and CP. A, Secondary structure analysis showing the $\mathrm{N}$ - and C-terminal helices of the p33 protein (amino acid residues 1 to 50 and 251 to 300, respectively) using the PSIPRED Protein Analysis Workbench prediction tool. B, Maximum projection images of Nicotiana benthamiana leaves agroinfiltrated with constructs nEYFP:p33 $\mathrm{N} 30+$ cEYFP (a), nEYFP:p33N30 + cEYFP (b), nEYFP + cEYFP:CP (c), nEYFP + cEYFP: p20 (d), and nEYFP + cEYFP:p23, or with constructs as described in each image (e). Nuclei were marked with cyan fluorescent protein targeted to the nucleus. Photos were taken at 4 days postinfiltration. Bar $=20 \mu \mathrm{m}$. 
extended host range, interacts with three viral proteins, all of which play a role in mitigation of the RNA silencing-based plant antiviral response. These observations pose a hypothesis that the interaction between those protein partners effectuates virus infection in the selective hosts. Further research is needed for better understanding of how viral proteins and protein complexes mediate virus-host interactions in the complex citrus-CTV pathosystem.

\section{MATERIALS AND METHODS}

\section{Generation of constructs for the YTH assay.}

The CTV ORFs of L1, L2, p6, HSP70h, p61, CPm, CP, p18, p13, p20, and p23 were amplified by PCR, using Cloneamp $\mathrm{HiFi}$ polymerase (Clontech Laboratories, Inc.), using oligonucleotides listed in Supplementary Table 1, and were cloned into the pGBKT7 (pBD) and pGADT7 (pAD) vectors containing upstream GAL4 binding and activation sequences, respectively, by homologous recombination, using the In-Fusion Advantage PCR cloning kit (Clontech Laboratories, Inc.). The constructs expressing a truncated p33 lacking its TMD (pAD-p33 $\triangle \mathrm{TMD}$ and pBD-p33 $\triangle \mathrm{TMD}$ ) were described previously (Kang et al. 2017). The pBD- and pAD-based plasmids were introduced into Stellar competent cells (Clontech Laboratories, Inc.) using heat-shock transformation. Transformed cells were selected on the Luria-Bertani (LB) agar media supplemented with kanamycin $(50 \mu \mathrm{g} / \mathrm{ml})$ or ampicillin $(100 \mu \mathrm{g} / \mathrm{ml})$ for $\mathrm{pBD}$ or $\mathrm{pAD}$ clones, respectively. Selected clones were screened for the presence of the cloned CTV genes by restriction enzyme digestion using $N d e \mathrm{I}$ and $\mathrm{XhoI}$ for $\mathrm{pAD}$ clones or $N d e \mathrm{I}$ and $P s t \mathrm{I}$ for $\mathrm{pBD}$ clones, followed by sequencing confirmation (Psomagen).

\section{Generation of constructs for the $\mathrm{BiFC}$ assay.}

The cDNA of the CP, CPm, p13, p18, and p20 genes from the T36 isolate of CTV were amplified by PCR, using sets of oligonucleotides listed in Supplementary Table 2. The PCR products were digested with $\mathrm{XhoI}$ and $\mathrm{XmaI}$ restriction endonucleases and substituted for the corresponding fragment in the pSAT vectors (Tzfira et al. 2005) pSAT6-nEYFP-C1 (pSAT2884, GenBank accession number DQ168994) and pSAT1-cEYFPC1(B) (pSAT3076, GenBank accession number DQ168996), encoding the $\mathrm{N}$ - or C-terminal fragments of EYFP, respectively, which were also digested with XhoI and XmaI restriction endonucleases. The nEYFP:p23 and cEYFP:p23 constructs, in which each of the two halves of EYFP fused at the C-terminal end of the p23 ORF, were cloned in a similar way, except that pSAT1A-nEYFP-N1 (pSAT3079, GenBank accession number DQ169001) and pSAT1A-cEYFP-N1 (pSAT3080, GeneBank accession number DQ169000) were used in this step. Engineered pSAT-based plasmids were used as the templates to amplify the cDNA cassettes to be subsequently cloned into the pCASS-4N binary vector, using a set of oligonucleotides producing PCR products with a blunt end and the KpnI recognition site on the other end. The PCR products were digested with $K p n I$ restriction endonuclease and were substituted for the corresponding fragment in the pCASS-4N plasmid, which was digested with $S t u \mathrm{I}$ and $K p n \mathrm{I}$ restriction endonucleases. Selected clones were screened on the LB agar media supplemented with kanamycin $(50 \mu \mathrm{g} / \mathrm{ml})$ and were confirmed by sequencing (Psomagen). The construction of nEYFP:p33 $\Delta$ N30 and nEYFP: p33N30 was described previously (Kang et al. 2017). PCR was carried out using Phusion Flash PCR master mix (Thermo Fischer Scientific). Restriction enzymes were obtained from New England Biolabs (Ipswich). PCR products were purified using NucleoSpin gel and PCR Clean-up (Macherey-Nagel). QIAprep Spin Miniprep kit (Qiagen) was used for plasmid purification. Gel extraction was performed using QIAQuick and QIAEX II gel extraction kit (Qiagen).

\section{Generation of the fluorescent protein-tagged constructs for co-IP and confocal microscopy assays.}

The generation of constructs expressing the GFP- or RFPtagged proteins examined in this work was conducted using overlap-extension PCR (OE-PCR) as described previously (Bak and Folimonova 2015; Kang et al. 2015). The new constructs were produced by OE-PCR using two PCR fragments, one containing a fusion of the $5^{\prime}$ nontranslated region (NTR) of tobacco etch virus (TEV) (Carrasco et al. 2007) to the $5^{\prime}$-end region of the GFP or RFP gene and the other containing an amplified complete ORF of a CTV gene (p20 or CP) or that of a FHV B2 protein, using sets of oligonucleotides listed in Supplementary Table 3 . The OE-PCR products were digested with KpnI restriction endonuclease. The digested products were substituted for the corresponding fragment in the pCASS-4N plasmid, which was digested with StuI and KpnI restriction endonucleases. For the constructs expressing GFP or RFP fused to the C-terminal end of p23, the pSAT3079-p23:nEYFP construct (described above) was used as a template to amplify the first PCR fragment, comprising the TEV NTR and p23 ORF, using a forward primer containing the TEV NTR sequence (TEV FW) and a reverse primer (p23-GFP RV or p23-RFP RV). The second PCR fragment consisting of a complete GFP or RFP ORFs was amplified using oligonucleotide pairs P23-GFP FW and KpnI GFP RV or P23-RFP FW and KpnI RFP RV, respectively (Supplementary Table 3 ). The subsequent OEPCR products were then introduced into the pCASS-4N plasmid in a similar fashion as the other constructs described earlier in this section.

\section{YTH analysis.}

Small-scale lithium acetate-mediated transformation of Saccharomyces cerevisiae Y2HGold was used for the GAL4based YTH system (Matchmaker Gold, Clontech Laboratories, Inc.) as described previously (Kang et al. 2017). S. cerevisiae Y2HGold was cotransformed with each pair of the generated pBD and pAD constructs described above, using the Yeastmaker yeast transformation system 2 (Clontech Laboratories, Inc.). Transformed cells were initially plated on the SD minimal media with DDO lacking tryptophan and leucine (SD/-Trp-Leu) and were incubated for 3 days at $30^{\circ} \mathrm{C}$ to screen for cotransformed yeast cells. The colonies grown on DDO SD were subsequently restreaked on a set of selective SD minimal media including TDO lacking tryptophan, leucine, and histidine (SD/-Trp-Leu-His) and QDO lacking tryptophan, leucine, histidine, and adenine (SD/-Trp-Leu-His-Ade). pAD-T (GAL4 activation domain fused to the SV40 large T-antigen), pBD-53 (GAL4 binding domain fused to the murine p53), and pBD-Lam (GAL4 binding domain fused to lamin) were supplied as positive and negative controls by the manufacturer.

\section{Agroinfiltration of constructs into $N$. benthamiana.}

Agroinfiltration of the constructs cloned in the binary vector plasmids (described above) was conducted as previously described (Ambrós et al. 2011; Kang et al. 2015). Briefly, plasmids were introduced by heat shock into Agrobacterium tumefaciens GV3101 and were selected on the LB agar plates containing two antibiotics ( $50 \mu \mathrm{g}$ of rifampicin per milliliter and $25 \mu \mathrm{g}$ of kanamycin per milliliter). Cells collected from an overnight culture of a selected single colony by centrifugation at $8,000 \mathrm{rpm}$ for $5 \mathrm{~min}$ were gently resuspended in a buffer containing $10 \mathrm{mM}$ 2-(N-morpholino) ethane sulfonic acid (MES), $\mathrm{pH}$ 5.85), $10 \mathrm{mM} \mathrm{MgCl}$, and $150 \mathrm{mM}$ acetosyringone at optical density at $600 \mathrm{~nm}=1.0$ for any binary construct expressing a 
single viral ORF or 0.1 for a binary construct expressing a fulllength CTV (pCTV-GFP, pCTV-RFP, or pCTV-GFP:p33 [Bergua et al. 2014; El-Mohtar and Dawson 2014; Kang et al. 2015]) or a CTV variant lacking the p33 gene (pCTVRFP: $\triangle \mathrm{p} 33$ or pCTV-GFP: $\Delta$ p33 [Bergua et al. 2014; Sun and Folimonova 2019]). Following incubation for $3 \mathrm{~h}$ at room temperature without shaking, the suspensions were coinfiltrated into the abaxial side of 6-week-old $N$. benthamiana plants using a needless syringe. Transgenic $N$. benthamiana plants expressing cyan fluorescent protein targeted to the nucleus (CFP:H2B [Martin et al. 2009]) were used to locate the nucleus in the fluorescence microscopy analysis.

\section{Co-IP and immunoblotting analysis.}

Total protein was extracted from $1 \mathrm{~g}$ of infiltrated leaves of $N$. benthamiana collected at 4 days postinfiltration (dpi) by grinding in $4 \mathrm{ml}$ of buffer Q $(50 \mathrm{mM}$ Tris- $\mathrm{HCl}, \mathrm{pH} 7.5,10 \mathrm{mM}$ EDTA, $150 \mathrm{mM} \mathrm{NaCl}, 10 \%$ glycerol) with $1 \%$ Triton X-100 and proteinase inhibitor cocktail (PIC) (AEBSF, bestatin, E-64, leupetin, pepstatin A and 1,10-phenanthroline [SigmaAldrich]). The homogenate was incubated on ice for $1 \mathrm{~h}$ with shaking and was then clarified by centrifugation at 3,000 $\times g$ for $10 \mathrm{~min}$ at $4^{\circ} \mathrm{C}$. Total protein extracts were immunoprecipitated using GFP-trap (anti-GFP antibody-conjugated agarose beads [Chromotek Inc.]) as described previously (Kang et al. 2017). Briefly, the supernatant was diluted in buffer Q, using a 1:4 (supernatant/buffer Q) ratio, and was incubated overnight at $4^{\circ} \mathrm{C}$ with $15 \mu \mathrm{l}$ of GFP trapping agarose beads. The GFP trapping agarose beads were then washed with buffer $\mathrm{Q}$ three times. For immunoblot analysis, washed beads were mixed with an equal volume of the $2 \times$ sample loading buffer $(125 \mathrm{mM}$ Tris- $\mathrm{HCl}, 4 \%$ sodium dodecyl sulfate [SDS], $20 \%$ glycerol, and $0.01 \%$ bromophenol blue) supplemented with $0.1 \mathrm{M}$ dithiothreitol and boiled for $10 \mathrm{~min}$. Mixtures were briefly centrifuged prior to loading and were electrophoresed through the SDS-polyacrylamide gel (Bio-Rad) and electro-transferred to a polyvinylidene difluoride membrane (Thermo Fisher Scientific). The membrane was blocked with $1 \times$ TBS-T $(137 \mathrm{mM}$ $\mathrm{NaCl}, 27 \mathrm{mM} \mathrm{KCl}, 250 \mathrm{mM}$ Tris- $\mathrm{HCl}$, and 1\% Tween-20) containing $5 \%$ skim milk for an hour at room temperature prior to beng probed with the corresponding antibodies (anti-GFP [Santa Cruz Biotechnology], anti-RFP [Thermo Fisher Scientific], antinYFP and anticYFP [Agrisera], antip33 and anti-CP [Kang et al. 2015], and antip20 and antip23 [described below]) for overnight (diluted at 1:1,000). Goat antirabbit or antimouse immunoglobulin $\mathrm{G}$ conjugated to horseradish peroxidase was used as a secondary antibody (diluted at 1:20,000) (Abcam or Santa Cruz Biotechnology), and the signal was visualized on the chemiluminescence film (X-OMAT LS; Thermo Fisher Scientific) in a dark room.

\section{Subcellular fractionation.}

Fractionation of $N$. benthamiana total protein extract was carried out as previously described (Kang et al. 2015). Briefly, $1 \mathrm{~g}$ of infiltrated leaves of $N$. benthamiana collected at $4 \mathrm{dpi}$ was ground in $2 \mathrm{ml}$ of buffer Q with PIC. The crude extract was filtered through Miracloth (EMD Millipore). Filtered extract $(200 \mu \mathrm{l})$ was kept as the total fraction $(\mathrm{T})$, the rest $(1.8 \mathrm{ml}$ of the filtered extract) was then centrifuged at $3,000 \times g$ for $10 \mathrm{~min}$ at $4^{\circ} \mathrm{C}$. Some of the supernatant $(200 \mu \mathrm{l})(\mathrm{S} 3)$ was kept, and the rest $(1.6 \mathrm{ml})$ of the supernatant was subsequently centrifuged at $30,000 \times g$ for $30 \mathrm{~min}$ at $4^{\circ} \mathrm{C}$ to separate the soluble (S30) and the microsomal (P30) fractions. The pellet obtained after $3,000 \times g$ centrifugation $(\mathrm{P} 3)$ was resuspended in $1.8 \mathrm{ml}$ of buffer Q. The pellet obtained after $30,000 \times g$ centrifugation (P30) was resuspended in $1.6 \mathrm{ml}$ of buffer Q. The protein loading buffer with PIC was added into all fractions. The same volume amount of each fraction was subjected to immunoblotting analysis.

\section{Production of anti-p20 and -p23 antibodies.}

Based on the hydrophilicity plot, two regions of the $\mathrm{p} 20$ protein (aa residues 56 to 72 [NGDHQDGHHEMGEHKSRC] and 134 to 151 [CKAVLSDLSRAHKLDFSER]) and three regions of the p23 protein (aa residues 70 to 86 [DCGRKHDKGLKTERKCK], 100 to 117 [CLMHDPVKYLNKRKARAFS], and 142 to 158 [CEREKTRLARRHPMRSPE]) were selected for antipeptide antibody production. Custom antibody production using rabbits was completed by Genemed Synthesis Inc.

\section{Laser-scanning confocal microscopy.}

Infiltrated leaves of $N$. benthamiana were observed at 4 or 5 dpi, using a Leica TCS SP5 confocal laser scanning microscope system (Leica Micro-Systems). GFP, RFP, EYFP, and CFP fluorescence signals were detected with excitation at 488-, 543-, 514-, and 405-nm lasers, respectively, and emission capture at 499 to 530,555 to 650,520 to 600 , and 460 to $480 \mathrm{~nm}$, respectively. Images were captured using a $63 \times / 1.4$ oilimmersion objective. ImageJ software was employed to process captured images (Schneider et al. 2012).

\section{In silico sequence analysis.}

The secondary structure of CTV p33 was analyzed by PSIPRED Protein Analysis Workbench (Buchan et al. 2013), using the aa sequence of the $\mathrm{p} 33$ protein of the T36 isolate of CTV (EU937521).

\section{ACKNOWLEDGMENTS}

The authors thank L.-Y. Lee (Purdue University) for kindly providing pSAT plasmids and M. Goodin (University of Kentucky) for generously providing CFP:H2B-transgenic Nicotiana benthamiana seeds.

\section{AUTHOR-RECOMMENDED INTERNET RESOURCE}

PSIPRED Protein Analysis Workbench prediction tool: http://bioinf.cs.ucl.ac.uk/psipred

\section{LITERATURE CITED}

Agranovsky, A. A. 1996. Principles of molecular organization, expression, and evolution of closteroviruses: Over the barriers. Adv. Virus Res. 47: 119-158.

Agranovsky, A. A., Lesemann, D. E., Maiss, E., Hull, R., and Atabekov, J. G. 1995. "Rattlesnake" structure of a filamentous plant RNA virus built of two capsid proteins. Proc. Natl. Acad. Sci. U.S.A. 92:2470-2473.

Alzhanova, D. V., Hagiwara, Y., Peremyslov, V. V., and Dolja, V. V. 2000. Genetic analysis of the cell-to-cell movement of beet yellows closterovirus. Virology 268:192-200.

Ambrós, S., El-Mohtar, C., Ruiz-Ruiz, S., Peña, L., Guerri, J., Dawson, W. O., and Moreno, P. 2011. Agroinoculation of Citrus tristeza virus sauses systemic infection and symptoms in the presumed nonhost Nicotiana benthamiana. Mol. Plant-Microbe Interact. 24:1119-1131.

Bak, A., and Folimonova, S. Y. 2015. The conundrum of a unique protein encoded by citrus tristeza virus that is dispensable for infection of most hosts yet shows characteristics of a viral movement protein. Virology 485:86-95.

Bar-Joseph, M., Garnsey, S. M., and Gonsalves, D. 1979. The closteroviruses: A distinct group of elongated plant viruses. Adv. Virus Res. 25: 93-168.

Barton, D. A., Roovers, E. F., Gouil, Q., da Fonseca, G. C., Reis, R. S., Jackson, C., Overall, R. L., Fusaro, A. F., and Waterhouse, P. M. 2017. Live cell imaging reveals the relocation of dsRNA binding proteins upon viral infection. Mol. Plant-Microbe Interact 30:435-443.

Bergua, M., Kang, S.-H., and Folimonova, S. Y. 2016. Understanding superinfection exclusion by complex populations of Citrus tristeza virus. Virology 499:331-339.

Bergua, M., Zwart, M. P., El-Mohtar, C., Shilts, T., Elena, S. F., and Folimonova, S. Y. 2014. A viral protein mediates superinfection exclusion at 
the whole-organism level but is not required for exclusion at the cellular level. J. Virol. 88:11327-11338.

Block, A., Widhalm, J. R., Fatihi, A., Cahoon, R. E., Wamboldt, Y., Elowsky, C., Mackenzie, S. A., Cahoon, E. B., Chapple, C., Dudareva, N., and Basset, G. J. 2014. The origin and biosynthesis of the benzenoid moiety of ubiquinone (coenzyme Q) in Arabidopsis. Plant Cell 26: 1938-1948.

Brito, A. F., and Pinney, J. W. 2017. Protein-protein interactions in virus-host systems. Front. Microbiol. 8:1557.

Buchan, D. W., Minneci, F., Nugent, T. C., Bryson, K., and Jones, D. T. 2013. Scalable web services for the PSIPRED Protein Analysis Workbench. Nucleic Acids Res. 41 (W1):W349-\$357.

Carrasco, P., Daròs, J. A., Agudelo-Romero, P., and Elena, S. F. 2007. A real-time RT-PCR assay for quantifying the fitness of tobacco etch virus in competition experiments. J. Virol. Methods 139:181-188.

Çevik, B. 2013. The RNA-dependent RNA polymerase of Citrus tristeza virus forms oligomers. Virology 447:121-130.

Dawson, W. O., Garnsey, S. M., Tatineni, S., Folimonova, S. Y., Harper, S. J., and Gowda, S. 2013. Citrus tristeza virus-host interactions. Front. Microbiol. 4:88.

Dolja, V. V., Karasev, A. V., and Koonim, E. V. 1994. Molecular biology and evolution of closteroviruses: Sophisticated build-up of large RNA genomes. Annu. Rev. Phytopathol. 32:261-285.

Dolja, V. V., Kreuze, J. F., and Valkonen, J. P. 2006. Comparative and functional genomics of closteroviruses. Virus Res. 117:38-51.

El-Mohtar, C., and Dawson, W. O. 2014. Exploring the limits of vector construction based on Citrus tristeza virus. Virology 448:274-283.

Fagoaga, C., Pensabene-Bellavia, G., Moreno, P., Navarro, L., Flores, R., and Peña, L. 2011. Ectopic expression of the p23 silencing suppressor of Citrus tristeza virus differentially modifies viral accumulation and tropism in two transgenic woody hosts. Mol. Plant Pathol. 12:898-910.

Folimonova, S. Y. 2012. Superinfection exclusion is an active viruscontrolled function that requires a specific viral protein. J. Virol. 86: 5554-5561.

Folimonova, S. Y., Robertson, C. J., Shilts, T., Folimonov, A. S., Hilf, M. E., Garnsey, S. M., and Dawson, W. O. 2010. Infection with strains of Citrus tristeza virus does not exclude superinfection by other strains of the virus. J. Virol. 84:1314-1325.

Gowda, S., Satyanarayana, T., Davis, C. L., Navas-Castillo, J., AlbiachMartí, M. R., Mawassi, M., Valkov, N., Bar-Joseph, M., Moreno, P., and Dawson, W. O. 2000. The p20 gene product of Citrus tristeza virus accumulates in the amorphous inclusion bodies. Virology 274:246-254.

Hilf, M. E., Karasev, A. V., Pappu, H. R., Gumpf, D. J., Niblett, C. L., and Garnsey, S. M. 1995. Characterization of citrus tristeza virus subgenomic RNAs in infected tissue. Virology 208:576-582.

Kang, S.-H., Atallah, O. O., Sun, Y.-D., and Folimonova, S. Y. 2018. Functional diversification upon leader protease domain duplication in the Citrus tristeza virus genome: Role of RNA sequences and the encoded proteins. Virology 514:192-202.

Kang, S.-H., Bak, A., Kim, O.-K., and Folimonova, S. Y. 2015. Membrane association of a nonconserved viral protein confers virus ability to extend its host range. Virology 482:208-217.

Kang, S.-H., Dao, T. N. M., Kim, O.-K., and Folimonova, S. Y. 2017. Selfinteraction of Citrus tristeza virus p33 protein via N-terminal helix. Virus Res. 233:29-34.

Kang, S.-H., Sun, Y.-D., Atallah, O. O., Huguet-Tapia, J. C., Noble, J. D., and Folimonova, S. Y. 2019. A long non-coding RNA of Citrus tristeza virus: Role in the virus interplay with the host immunity. Viruses 11:436.

Karasev, A. V. 2000. Genetic diversity and evolution of closteroviruses. Annu. Rev. Phytopathol. 38:293-324.

Karasev, A. V., Boyko, V. P., Gowda, S., Nikolaeva, O. V., Hilf, M. E., Koonin, E. V., Niblett, C. L., Cline, K., Gumpf, D. J., Lee, R. F., Garnsey, S. M., Lewandowski, D. J., and Dawson, W. O. 1995. Complete sequence of the citrus tristeza virus RNA genome. Virology 208:511-520.

Karasev, A. V., Hilf, M. E., Garnsey, S. M., and Dawson, W. O. 1997. Transcriptional strategy of closteroviruses: Mapping the $5^{\prime}$ termini of the citrus tristeza virus subgenomic RNAs. J. Virol. 71:6233-6236.

Linnik, O., Liesche, J., Tilsner, J., and Oparka, K. J. 2013. Unraveling the structure of viral replication complexes at super-resolution. Front. Plant Sci. 4:6.

Lõhmus, A., Varjosalo, M., and Mäkinen, K. 2016. Protein composition of 6K2-induced membrane structures formed during Potato virus A infection. Mol. Plant Pathol. 17:943-958.
Lu, R., Folimonov, A., Shintaku, M., Li, W. X., Falk, B. W., Dawson, W. O., and Ding, S. W. 2004. Three distinct suppressors of RNA silencing encoded by a $20-\mathrm{kb}$ viral RNA genome. Proc. Natl. Acad. Sci. U.S.A. 101:15742-15747.

Martin, K., Kopperud, K., Chakrabarty, R., Banerjee, R., Brooks, R., and Goodin, M. M. 2009. Transient expression in Nicotiana benthamiana fluorescent marker lines provides enhanced definition of protein localization, movement and interactions in planta. Plant J. 59:150-162.

Monsion, B., Incarbone, M., Hleibieh, K., Poignavent, V., Ghannam, A., Dunoyer, P., Daeffler, L., Tilsner, J., and Ritzenthaler, C. 2018. Efficient detection of long dsRNA in vitro and in vivo using the dsRNA binding domain from FHV B2 protein. Front. Plant Sci. 9:70.

Moreno, P., Ambrós, S., Albiach-Martí, M. R., Guerri, J., and Peña, L. 2008. Citrus tristeza virus: A pathogen that changed the course of the citrus industry. Mol. Plant Pathol. 9:251-268.

Nchongboh, C. G., Wu, G. W., Hong, N., and Wang, G. P. 2014. Proteinprotein interactions between proteins of Citrus tristeza virus isolates. Virus Genes 49:456-465.

Peremyslov, V. V., Pan, Y. W., and Dolja, V. V. 2004. Movement protein of a closterovirus is a type III integral transmembrane protein localized to the endoplasmic reticulum. J. Virol. 78:3704-3709.

Ruiz-Ruiz, S., Soler, N., Sánchez-Navarro, J., Fagoaga, C., López, C. Navarro, L., Moreno, P., Peña, L., and Flores, R. 2013. Citrus tristeza virus $\mathrm{p} 23$ : Determinants for nucleolar localization and their influence on suppression of RNA silencing and pathogenesis. Mol. Plant-Microbe Interact 26:306-318.

Ruiz-Ruiz, S., Spanò, R., Navarro, L., Moreno, P., Peña, L., and Flores, R. 2018. Citrus tristeza virus co-opts glyceraldehyde 3-phosphate dehydrogenase for its infectious cycle by interacting with the viral-encoded protein p23. Plant Mol. Biol. 98:363-373.

Satyanarayana, T., Gowda, S., Ayllón, M. A., Albiach-Martí, M. R., Rabindran, S., and Dawson, W. O. 2002. The p23 protein of citrus tristeza virus controls asymmetrical RNA accumulation. J. Virol. 76: 473-483.

Satyanarayana, T., Gowda, S., Ayllón, M. A., and Dawson, W. O. 2004 Closterovirus bipolar virion: Evidence for initiation of assembly by minor coat protein and its restriction to the genomic RNA 5' region. Proc. Natl. Acad. Sci. U.S.A. 101:799-804.

Satyanarayana, T., Gowda, S., Mawassi, M., Albiach-Martí, M. R., Ayllón, M. A., Robertson, C., Garnsey, S. M., and Dawson, W. O. 2000 Closterovirus encoded HSP70 homolog and p61 in addition to both coat proteins function in efficient virion assembly. Virology 278:253-265.

Saxena, P., and Lomonossoff, G. P. 2014. Virus infection cycle events coupled to RNA replication. Annu. Rev. Phytopathol. 52:197-212.

Schneider, C. A., Rasband, W. S., and Eliceiri, K. W. 2012. NIH Image to ImageJ: 25 years of image analysis. Nat. Methods 9:671-675.

Stagljar, I., and Fields, S. 2002. Analysis of membrane protein interactions using yeast-based technologies. Trends Biochem. Sci. 27:559-563.

Sun, Y. D., and Folimonova, S. Y. 2019. The p33 protein of Citrus tristeza virus affects viral pathogenicity by modulating a host immune response. New Phytol. 221:2039-2053.

Tatineni, S., and Dawson, W. O. 2012. Enhancement or attenuation of disease by deletion of genes from Citrus tristeza virus. J. Virol. 86 7850-7857.

Tatineni, S., Gowda, S., and Dawson, W. O. 2010. Heterologous minor coat proteins of Citrus tristeza virus strains affect encapsidation, but the coexpression of HSP70h and p61 restores encapsidation to wild-type levels. Virology 402:262-270.

Tatineni, S., Robertson, C. J., Garnsey, S. M., Bar-Joseph, M., Gowda, S., and Dawson, W. O. 2008. Three genes of Citrus tristeza virus are dispensable for infection and movement throughout some varieties of citrus trees. Virology 376:297-307.

Tatineni, S., Robertson, C. J., Garnsey, S. M., and Dawson, W. O. 2011. A plant virus evolved by acquiring multiple nonconserved genes to extend its host range. Proc. Natl. Acad. Sci. U.S.A. 108:17366-17371.

Tian, T., Rubio, L., Yeh, H.-H., Crawford, B., and Falk, B. W. 1999. Lettuce infectious yellows virus: In vitro acquisition analysis using partially purified virions and the whitefly Bemisia tabaci. J. Gen. Virol. 80: 1111-1117

Tzfira, T., Tian, G. W., Lacroix, B., Vyas, S., Li, J., Leitner-Dagan, Y., Krichevsky, A., Taylor, T., Vainstein, A., and Citovsky, V. 2005. pSAT vectors: A modular series of plasmids for autofluorescent protein tagging and expression of multiple genes in plants. Plant Mol. Biol. 57:503-516. 